Journal of Interpersonal Violence

A Survey of Police Officers' and

Prosecutors' Beliefs

About Crime Victim Behaviors
(C) The Author(s) 2009

Reprints and permission: http://www. sagepub.com/journalsPermissions.nav DOI: 10.1 I 77/0886260509340535 http://jiv.sagepub.com

@SAGE

\title{
Karl Ask'
}

\begin{abstract}
A survey of police officers $(n=21 \mathrm{I})$ and prosecutors $(n=190)$ in Sweden was conducted to assess law personnel's beliefs about the behaviors and reactions of victims of violent crimes. There were considerable differences in the expected behavioral display of different types of crime victims, with rape and domestic assault victims seen as particularly prone to expressive self-presentation and self-blame. Despite empirical evidence showing otherwise, most respondents thought that crime victims' nonverbal and emotional expression is to some extent related to the truthfulness of their accounts. However, educational efforts appeared to have a corrective influence on such beliefs. The perceived prevalence of false reports differed across crime types, with rape and mugging receiving particularly high estimates. Police officers believed false reports to be more common than did prosecutors. Time constraints were seen, especially by prosecutors, as an impediment to appropriate treatment of crime victims. Potential
\end{abstract}

\footnotetext{
'University of Gothenburg, Sweden
}

\section{Corresponding Author:}

Karl Ask, Department of Psychology, University of Gothenburg, P.O. Box 500, SE 405 30,

Gothenburg, Sweden

Email:karl.ask@psy.gu.se 
Journal of Interpersonal Violence $X X(X)$

explanations for occupational differences and limitations associated with the survey methodology are discussed.

\section{Keywords}

crime victims, rape, self-presentation, false reports, beliefs

Given the traumatic nature of violent crimes, it is critical that professionals involved in the legal process treat crime victims with consideration of their special needs and concerns. The failure to do so may adversely affect the victim's well-being and long-term recovery from the trauma (Campbell et al., 1999) and lessen the victim's ability and willingness to cooperate in the current and future criminal cases (Bard \& Sangrey, 1986). Another important consequence, which has received increased scholarly attention in recent years, is that the failure to take into account the psychological reactions of a victim may result in misinterpretations of the victim's demeanor. For instance, the composed and numbed behavior of a rape victim, lacking signs of emotional distress, during a police interview may erroneously be construed as a sign that the victim is not telling the truth about the event (Kaufmann, Drevland, Wessel, Overskeid, \& Magnussen, 2003; Winkel \& Koppelaar, 1991). This has serious implications for cases where physical evidence is lacking and the legal outcome largely depends on the judged credibility of the accuser and the accused, which is often true in cases of rape and other sex-related crimes. Unfortunately, legal professionals, as well as lay people, are very poor at detecting deception when merely observing a statement, rarely performing better than what would be predicted by chance alone (i.e., $50 \%$ in a dichotomous lie/truth judgment; Bond \& DePaulo, 2006; Vrij, 2008). In addition, the cues that people report relying on when assessing veracity have been found not to be consistently related to truthfulness or deception (DePaulo et al., 2003; Sporer \& Schwandt, 2007). Hence, an important measure to prevent misattribution of victims' demeanor should be to equip legal professionals with accurate knowledge. As a first step in this process, the present research sought to document some of the existing beliefs by means of a survey among police officers and prosecutors.

The psychological consequences of criminal victimization have been studied systematically for more than three decades. In a pioneering study, Burgess and Holmstrom (1974) examined the physical and psychological reactions of rape victims who were admitted to the emergency department of a major city hospital. The researchers found evidence for a so-called rape trauma syndrome. That is, most of the female rape victims displayed a 
similar sequence of reactions, characterized by an initial acute phase and a long-term reorganization phase. In the acute phase, a number of somatic manifestations were present (e.g., physical trauma, muscle tension) as well as a range of emotional reactions (e.g., fear, self-blame). Two styles of self-presentation were observed: the expressive style - in which negative emotions were evident through crying, sobbing, and tenseness - and the controlled style - where any emotional reactions were hidden and a calm, composed behavior was displayed. The two styles of expression were equally common among the rape victims. The long-term reorganization phase involved behaviors that helped victims cope with the trauma and restore a functional lifestyle, but it was frequently accompanied by persistent symptoms in the form of nightmares or phobias (Burgess \& Holmstrom, 1974). The observed pattern was later found to be reliable across several studies (for a review, see Frieze, Hymer, \& Greenberg, 1987). However, similar to the Burgess and Holmstrom study, most research in the area has focused on the long-term psychological impact of the crime (for a review, see Weaver \& Clum, 1995) or the clinical treatment and recovery of the victim (for a review, see Amstadter, McCart, \& Ruggiero, 2007), rather than the behaviors and reactions displayed toward legal professionals. Furthermore, the primary focus has been on rape victims, whereas relatively few studies have investigated the differential impact of different types of crime. It appears, however, that assaultive and nonassaultive offenses often lead to the same types of long-term consequences, albeit of varying intensity (e.g., Lurigio, 1987; Norris \& Kaniasty, 1994; Wirtz \& Harrell, 1987). Recent evidence indicates that the peritraumatic responses (i.e., at the time of the offense) of rape victims tend to be more laden with emotions such as fear, guilt, humiliation, numbness, and a sense of betrayal than the responses of robbery and assault victims but that most of these emotions are quite common also in the latter category of victims (Kaysen, Morris, Rizvi, \& Resick, 2005). However, across all types of crimes, there is a substantial lack of documentation of the self-presentational styles that victims adopt when communicating with others about the event.

Relatively little is known about the beliefs that people hold about crime victims' self-presentation styles. However, recent experimental evidence suggests that people expect crime victims to act in a rather stereotypical manner. Kaufmann and his colleagues (2003) showed that the emotional display of a rape victim can influence judgments of the victim's credibility. When a victim's testimony was accompanied by negative emotional displays, such as sobbing and signs of despair, her story was perceived as more believable than when the same statement was given in a neutral (no 
emotions displayed) or incongruent (e.g., smiling) manner. The effect was first demonstrated with lay people as observers but was later replicated in a study of experienced police officers (Bollingmo, Wessel, Eilertsen, \& Magnussen, 2008). Interestingly, professional judges were found not to be influenced by the victim's emotional display (Wessel, Drevland, Eilertsen, \& Magnussen, 2006), perhaps indicating that their training in legal reasoning serves as a guard against behavioral misattribution - an explanation in need of further testing. Winkel and Koppelaar (1991) showed experimentally that a rape victim whose self-presentation was numbed not only was perceived as less credible but also was blamed more for the rape than an emotional victim. As further evidence for the existence of normative expectations about crime victims' emotional display, Rose, Nadler, and Clark (2006) found that victims are expected to react in a way that is proportional to the seriousness of the offense. An overly intense emotional display following a minor offense affected perceptions of a victim negatively, in the same way as did the failure to display strong emotions in relation to a serious crime (Rose et al., 2006). Taken together, the empirical evidence suggests that crime victims' behaviors are gauged against culturally shared stereotypes of normal reactions and that deviations from these stereotypes tend to lower victims' credibility. In addition, it appears that people are attuned to the nonverbal behavior of crime victims when trying to assess credibility, just as they have been found to do when judging criminal suspects and witnesses (Vrij, 2008). This is problematic, given a large body of research showing that nonverbal cues to deception are virtually nonexistent (Vrij, 2008; see also DePaulo et al., 2003).

Although the above studies make a rather strong case that certain behaviors are expected from crime victims, the actual content of such expectations was not directly addressed. Rather, normative beliefs were inferred from participants' responses to experimental manipulations. In addition, very few studies on the issue have examined professionals in the criminal justice system. To address these shortcomings, the present study surveyed the beliefs held by police officers and prosecutors - two groups that frequently meet crime victims and often make up a victim's only contact with the criminal justice system. The study also sought to compare the beliefs of these two occupational groups, as they may differ for several reasons. First, police officers meet a wider range of crime victims than do prosecutors, as the latter predominantly meet the subset of victims whose case proceeds to trial. Second, police officers engage in direct interaction with crime victims (e.g., through investigative interviews, crime-scene visits) more often than do prosecutors and hence may have a richer representation of crime victim 
behaviors. Third, because the two groups serve different functions in the legal system, police officers are motivated by different goals (e.g., solving crimes) than are prosecutors (e.g., winning cases), which in turn may influence their attitudes toward crime victims.

\section{Method}

\section{Procedure}

A random 8 of the 21 regional police authorities in Sweden were approached. Within these authorities, 17 senior officers responsible for teams of criminal investigators and patrol officers were contacted via telephone and agreed to distribute a questionnaire among their coworkers. A total of 304 paper questionnaires were then mailed for distribution. In addition, all 35 local public prosecution offices in Sweden were approached. An e-mail invitation containing a hyperlink to a Web-based, electronic version of the questionnaire was sent to the registrar at each office, who was asked to forward the invitation to prosecutors within the office. The distributors at both the police authorities and the prosecutor offices were asked to invite only personnel who encounter victims of violent crime as part of their work. The data collection took place in 2007 during a period of 2 months.

\section{Participants}

In total, 401 professionals-211 police officers and 190 prosecutorsresponded to the questionnaire. Hence, the response rate among police officers was $69.4 \%$. It was not possible to establish a response rate among prosecutors, as the actual number of invitations forwarded by administrators at each prosecutor office could not be controlled. It should be noted, however, that the number of prosecutors at the local offices in Sweden is about 650 . The demographic characteristics and professional experience of the respondents are presented in Table 1.

\section{The Questionnaire}

The items in the questionnaire were arranged into sections corresponding to different aspects of crime victim issues. Respondents were instructed to answer the questions with adult (i.e., 15 years or older) crime victims in mind. 
Journal of Interpersonal Violence $X X(X)$

Table I. Demographic Characteristics of the Police and Prosecutor Samples

\begin{tabular}{lcc}
\hline & & Sample \\
\cline { 2 - 3 } & Police & Prosecutors \\
\hline Gender & & \\
Female & $85(40.3 \%)$ & $98(51.6 \%)$ \\
Male & $126(59.7 \%)$ & $92(48.4 \%)$ \\
Age (years) & & \\
$25-34$ & $29(13.7 \%)$ & $28(14.7 \%)$ \\
$35-44$ & $46(21.8 \%)$ & $64(33.7 \%)$ \\
$45-54$ & $81(38.4 \%)$ & $67(35.3 \%)$ \\
$55-64$ & $51(24.2 \%)$ & $31(16.3 \%)$ \\
$\geq 65$ & $1(0.5 \%)$ & $0(0.0 \%)$ \\
Missing & $3(1.4 \%)$ & $0(0.0 \%)$ \\
Length of service (years) & $27(12.8 \%)$ & $40(21.1 \%)$ \\
$<5$ & $14(6.6 \%)$ & $39(20.5 \%)$ \\
$5-9$ & $35(16.6 \%)$ & $61(32.1 \%)$ \\
I0-19 & $63(29.9 \%)$ & $36(18.9 \%)$ \\
$20-29$ & $71(33.6 \%)$ & $14(7.4 \%)$ \\
$\geq 30$ & $1(0.5 \%)$ & $0(0.0 \%)$ \\
Missing & $81(38.4 \%)$ & $91(47.9 \%)$ \\
Special training & $129(61.1 \%)$ & $99(52.1 \%)$ \\
Yes & $1(0.5 \%)$ & $0(0.0 \%)$ \\
No & &
\end{tabular}

Note: Percentages indicate proportions within each sample.

aSpecial training on crime victims' psychological reactions and behaviors.

Behavioral observations. Two multipart questions addressed behavioral observations from participants' work with crime victims. Respondents were asked how often victims of rape, domestic assault, nondomestic battery, and mugging, respectively, (a) show an expressive self-presentational style (e.g., crying, despair, clear signs of distress) and (b) blame themselves for what happened. Each rating was made on a 5-point scale $(1=$ very rarely, $5=$ very often $)$.

Beliefs. Nine statements about crime-victim behaviors (see Table 2) were presented, and respondents were to indicate the perceived correctness of each statement on 5 -point scales $(1=$ totally incorrect, $5=$ totally correct $)$. In addition, respondents were asked to estimate the frequency of false reports (i.e., reports of crimes that in fact have not occurred) regarding rape, domestic assault, nondomestic battery, and mugging, respectively. A range 
Table 2. Police Officers' and Prosecutors' Beliefs About Crime Victim Behaviors

\begin{tabular}{|c|c|c|c|c|c|c|c|}
\hline $\begin{array}{l}\text { Occupational } \\
\text { group }\end{array}$ & $\begin{array}{c}\text { Totally } \\
\text { incorrect } \\
(\%)\end{array}$ & $\begin{array}{c}\text { Rather } \\
\text { incorrect } \\
(\%)\end{array}$ & $\begin{array}{c}\text { Partly } \\
\text { correct/ } \\
\text { incorrect } \\
(\%)\end{array}$ & $\begin{array}{c}\text { Rather } \\
\text { correct } \\
(\%)\end{array}$ & $\begin{array}{c}\text { Totally } \\
\text { correct } \\
(\%)\end{array}$ & $M(S D)$ & $p$ \\
\hline
\end{tabular}

I. A crime victim's display of emotions when telling about the crime is generally an indicator of the veracity of his/her statement

$\begin{array}{lllllll}\text { Police officers } & 7.1 & 19.4 & 55.0 & 17.5 & 0.5 & 2.8(0.8) \\ \text { Prosecutors } & 7.9 & 17.9 & 57.4 & 16.3 & 0.5 & 2.8(0.8)\end{array}$

2. A crime victim's willingness or reluctance to spontaneously give a detailed account of the crime is generally an indicator of the veracity of his/her statement
Police officers
12.8
32.7
40.3
13.7
$0.0 \quad 2.6(0.9)<.01$
Prosecutors
14.7
46.3
31.6
7.4
$0.0 \quad 2.3(0.8)$

3. The fact that a crime victim's expressive style violates my expectations is generally reason to examine the statement's veracity extra carefully
Police officers
7.1
40.8
38.9
12.3
$0.5 \quad 2.6(0.8)$
.67
Prosecutors
11.6
35.3
40.0
12.1
$0.5 \quad 2.5(0.9)$

4. A crime victim who displays negative emotions (e.g., crying, despair, clear signs of distress) during his/her testimony is generally more likely to be believed in court

Police officers

Prosecutors

$\begin{array}{rrrrrrr}2.8 & 14.7 & 53.6 & 21.3 & 1.4 & 3.0(0.8)<.001 \\ 1.6 & 6.8 & 45.3 & 39.5 & 6.8 & 3.4(0.8)\end{array}$

5. A crime victim who displays positive emotions (e.g., laughter, smiling) during his/her testimony is generally less likely to be believed in court
Police officers
2.8
12.3
49.8
26.5
Prosecutors

I.6 9.5
48.9
34.2
$\begin{array}{llll}1.9 & 3.1(0.8)<.05\end{array}$
$5.8 \quad 3.3(0.8)$

6. A crime victim's inability to report details about the event shortly after the crime (less than a day) is generally reason to question the veracity of the statement
Police officers
19.9
44.5
28.0
5.2
$0.5 \quad 2.2(0.8)<.05$
Prosecutors
II.I
$47.9 \quad 31.1$
7.9
I.I $2.4(0.8)$

7. Details that appear in a crime victim's memory after a period of time are generally less reliable than those that the victim can report right from the start
Police officers
20.4
42.7
30.3
5.7
$0.0 \quad 2.2(0.8)$

$\begin{array}{lllllll}\text { Prosecutors } & 12.6 & 47.4 & 32.1 & 5.8 & \text { I.I } & 2.3(0.8) \\ \text { 8. The displayed reactions to a violent } & \text { crime differ between } & \text { crime victims with }\end{array}$

$\begin{array}{lllllll}\text { Prosecutors } & 12.6 & 47.4 & 32.1 & 5.8 & \text { I.I } & 2.3(0.8) \\ \text { 8. The displayed reactions to a violent } & \text { crime differ between } & \text { crime victims with }\end{array}$

8 . The displayed reactions to a violent crime differ between crime victims with different cultural backgrounds
Police officers
I.4
7.1
40.3
38.9
II.4 $3.5(0.8)<.00$ I
Prosecutors
$3.2 \quad 16.8$
$46.8 \quad 26.8$
$4.23 .1(0.9)$

9. The type of relationship between the crime victim and the perpetrator generally influences the victim's expressive style and behavior

\begin{tabular}{llllllll} 
Police officers & 0.5 & 2.4 & 33.6 & 48.3 & 14.2 & $3.7(0.7)$ & .08 \\
Prosecutors & 1.1 & 3.2 & 17.9 & 61.6 & 14.7 & $3.9(0.7)$ & \\
\hline
\end{tabular}

Note: Means and standard deviations are based on the rating scale from I (totally incorrect) to 5 (totally correct). 
was to be estimated by indicating a minimum and a maximum percentage of all reports that were believed to be false.

Treatment of crime victims. By rating their agreement with a set of statements $(1=$ strongly disagree, $5=$ strongly agree $)$, respondents were to indicate (a) whether they find it an important part of their work to make crime victims feel well treated by the criminal justice system, (b) whether they would be able to treat crime victims better if they had more time, and (c) whether there is enough time for contacts with crime victims.

Self-rated knowledge. A final set of items were included to assess respondents' perceptions of their own knowledge about crime-victim behaviors, both in absolute terms $(1=$ very little knowledge, $5=$ very much knowledge $)$ and compared with their average colleague $(1=$ much less than average, $3=$ average, $5=$ much more than average). They were also asked whether they had undergone special training concerning crime victims' reactions and behaviors, and whether they had tried to increase their knowledge on the issue on their own initiative (e.g., by reading books, consulting research).

\section{Data Analysis}

The data were analyzed using the SPSS (version 15) statistical software. Parametric methods of analysis - analysis of variance (ANOVA), multivariate analysis of variance (MANOVA), and $t$ tests - were used for significance testing, based on the assumption that the rating scales used are best treated on an interval, rather than ordinal, level. For all analyses, a criterion level of $\alpha=.05$ was used.

\section{Results}

\section{Behavioral Observations}

Respondents thought that an expressive style of self-presentation is rather common among victims of all four crime types, as evidenced in an overall mean rating of $3.6(S D=0.7)$ on the 5-point scale. However, a 4 (crime type: rape vs. domestic assault vs. nondomestic battery vs. mugging) $\times 2$ (occupation: police officer vs. prosecutor) mixed ANOVA revealed a significant main effect of crime type, $F(3,1,143)=245.63, p<.001, \eta^{2}=.39$, indicating that the perceived frequency of expressive behavior varied between victims of different crimes. The highest rating was found for rape $(M=4.1, S D=0.9)$, followed by domestic assault $(M=3.9, S D=0.8)$, mugging $(M=3.2, S D=1.0)$, and nondomestic battery $(M=3.1, S D=0.9)$. 
The ratings of all four crime types differed significantly from each other, $p$ s $<.01$ (Bonferroni post hoc tests). There was no main effect of occupation, $F(1,380)=2.70, p=.10, \eta^{2}=.01$. However, a significant Crime Type $\times$ Occupation interaction emerged, $F(3,1,140)=3.39, p<.05, \eta^{2}=.01$. Simple-effect analyses showed that police officers thought that an expressive style was significantly more common among nondomestic battery victims $(M=3.2, S D=0.9)$ than did prosecutors $(M=2.9, S D=0.9)$, $F(1,1,140)=23.27, p<.001$. In addition, police officers found victims of mugging to more often display an expressive style $(M=3.3, S D=1.0)$ than did prosecutors $(M=3.1, S D=0.9), F(1,1,140)=5.41, p<.05$. No occupational differences emerged for domestic assault or rape victims.

Across crime types, respondents rated victim self-blame as rather uncommon $(M=2.5, S D=0.7)$. However, a second mixed ANOVA showed that there was significant variation between crimes, as indicated by a significant main effect of crime type, $F(3,1,134)=598.51, p<.001, \eta^{2}=.61$. Domestic assault victims were found to be most likely to put blame on themselves $(M=3.4, S D=1.0)$, followed by victims of rape $(M=3.0, S D=1.1)$, nondomestic battery $(M=1.9, S D=0.8)$, and mugging $(M=1.6, S D=0.8)$. The ratings of all four crime types differed significantly from each other by post hoc tests, $p<.001$ (Bonferroni). The main effect of occupation was also significant, $F(1,378)=4.46, p<.05, \eta^{2}=.01$, indicating that prosecutors saw victim self-blame as somewhat more common $(M=2.5, S E=0.1)$ than did police officers $(M=2.4, S E=0.1)$. Finally, the Occupation $\times$ Crime Type interaction was significant, $F(3,1,134)=10.49, p<.001, \eta^{2}=.03$. Simple-effect analyses revealed that prosecutors saw self-blame as more common among victims of rape $(M=3.1, S D=1.1)$ than did police officers $(M=2.9, S D=1.2), F(1,1,134)=7.65, p<.01$. Similarly, prosecutors rated self-blame as more common among victims of domestic assault $(M=3.6$, $S D=0.9)$ than did police officers $(M=3.2, S D=1.0), F(1,1,134)=37.69$, $p<.001$. No occupational differences were present regarding nondomestic battery or mugging.

\section{Self-Reported Beliefs}

Table 2 presents respondents' ratings of the nine statements about crime victim behaviors. Although respondents tended not to endorse extreme standpoints, frequently using the rating scale's midpoint (3), trends toward agreement or disagreement could be discerned. For instance, respondents tended to disagree with the propositions that a victim's inclination to give a spontaneous, detailed report is indicative of truthfulness, that a victim's inability to report details 
shortly after the crime is reason to question its veracity, and that details that appear after some time in a victim's memory are less reliable than those remembered initially. In contrast, there was a tendency to believe that the victim-offender relationship influences the victim's style of expression and behavior, and that the displayed reactions to a violent crime differ between victims with different cultural backgrounds.

Respondents assigned some weight to the nonverbal behavior of crime victims as an indicator of truthfulness. First, almost three quarters of the respondents $(73.8 \%)$ believed the proposition that a victim's emotional expression is indicative of veracity to be either partly correct/incorrect, rather correct, or totally correct. Second, more than half the participants $(52.4 \%)$ reported similar levels of agreement with the statement that an expectancy-violating style of expression is reason to question the veracity of a victim's statement extra carefully. As these beliefs are at odds with research findings on nonverbal indicators of truthfulness, it is of interest to know whether special training on crime victim issues has a corrective influence. A 2 (special training: yes vs. no) $\times 2$ (occupation: police officer vs. prosecutor) MANOVA was conducted on the two ratings. There was no main effect of occupation, nor was there an Occupation $\times$ Training interaction. However, the main effect of training was significant, Wilks' $\lambda=0.96, F(2$, $393)=7.59, p<.001, \eta^{2}=.04$. Respondents who had received training ( $43.0 \%$ of the total sample) believed significantly less strongly that emotional expressions were indicative of truthfulness $(M=2.7, S D=0.8)$ than did those who had not received training $(M=3.0, S D=0.8), F(1,394)=10.66, p<.01$, $\eta^{2}=.03$. Similarly, trained respondents were significantly less likely to see expectancy-violating nonverbal behavior as an indicator of veracity $(M=2.4$, $S D=0.8)$ than did untrained respondents $(M=2.7, S D=0.8), F(1,394)=$ $10.35, p<.01, \eta^{2}=.03$. Hence, special training appeared to have a positive influence on respondents' beliefs.

As evident in Table 2, the beliefs expressed by the two professional groups differed in some respects. Police officers were more likely than prosecutors to think that crime victims' inclination toward spontaneously giving a detailed account is indicative of veracity, $t(398)=2.77, p<.01$, $d=.28$, and that there are cultural differences in the ways victims react to violent crimes, $t(393)=4.64, p<.001, d=.47$. Prosecutors, however, were more likely than police officers to think that believability in court depends on a victim's expression of negative emotions, $t(386)=-5.01, p<.001, d=.51$, and positive emotions, $t(385)=-2.50, p<.05, d=.25$, and that an inability to report details shortly after the crime is reason to question the veracity of the victim's statement, $t(393)=-2.27, p<.05, d=.23$. 
Table 3. Means of Police Officers' and Prosecutors' Maximum and Minimum Estimates of the Frequency of False Reports by Crime Type

\begin{tabular}{lccllc}
\hline & \multicolumn{2}{c}{ Police officers } & & \multicolumn{2}{c}{ Prosecutors } \\
\cline { 2 - 3 } \cline { 6 - 7 } Type of crime & Minimum & Maximum & & Minimum & Maximum \\
\hline Rape & $15.5 \%(16.5)$ & $25.9 \%(21.1)$ & & $5.0 \%(7.0)$ & $12.2 \%(12.5)$ \\
Domestic assault & $5.1 \%(6.8)$ & $11.5 \%(11.0)$ & & $2.8 \%(3.8)$ & $9.3 \%(10.6)$ \\
Nondomestic battery & $6.2 \%(8.4)$ & $13.2 \%(12.2)$ & & $2.3 \%(3.4)$ & $8.1 \%(10.1)$ \\
Mugging & $8.7 \%(9.5)$ & $16.4 \%(13.2)$ & & $2.3 \%(3.3)$ & $7.9 \%(10.0)$ \\
\hline
\end{tabular}

Note: Each respondent contributed with both a minimum and a maximum estimate.

Numbers in brackets represent standard deviations.

\section{Estimates of False Reports}

Table 3 presents respondents' estimates of the frequency of false reports. The interpretation of these estimates is complicated by the fact that several respondents chose not to answer these items. The proportion of respondents who reported both a minimum and a maximum estimate was $80.5 \%$ for rape, $80.3 \%$ for domestic assault, $79.3 \%$ for nondomestic battery, and $77.6 \%$ for mugging. Respondents with missing data for any of the eight estimates were excluded from the following analysis, leaving data from a total of 306 respondents ( $76.3 \%$ of the total sample). A 4 (crime type: rape vs. domestic assault vs. nondomestic battery vs. mugging) $\times 2$ (estimate: minimum vs. maximum) $\times 2$ (occupation: police officer vs. prosecutor) mixed ANOVA, with the two first factors compared within participants, was performed on the estimates. As maximum estimates are by definition higher than minimum estimates, the main effect of estimate was highly significant, $F(1,304)=238.34, p<.001, \eta^{2}=.44$. The analysis further revealed a significant main effect of crime type, $F(3,912)=60.62, p<.001$, $\eta^{2}=.17$. Pairwise comparisons showed that the average false-report estimate for rape $(M=14.8, S E=0.9)$ was significantly higher than for mugging $(M=8.8, S E=0.5)$, nondomestic battery $(M=7.5, S E=0.5)$, and domestic assault $(M=7.1, S E=0.4)$, all $p \mathrm{~s}<.001$ (Bonferroni corrected). Estimates for mugging were in turn higher than for domestic assault $(p<.01)$ but not quite significantly higher than for nondomestic battery $(p=.054)$. Estimates for domestic assault and nondomestic battery did not differ from each other. The main effect of occupation was also significant, $F(1,304)=55.75, p<.001, \eta^{2}=.15$. Across crime types, police 
officers made higher estimates of false reports $(M=12.9, S E=0.6)$ than did prosecutors $(M=6.2, S E=0.7)$.

Three of the four possible interactions in the analysis were significant. First, there was evidence for a Crime Type $\times$ Occupation interaction, $F(3,912)=22.26, p<.001, \eta^{2}=.07$. Among police officers, estimates for all crime types differed from each other, $p \mathrm{~s}<.01$, with the exception of domestic assault and nondomestic battery, $p=.29$ (Bonferroni). Among prosecutors, however, estimates for rape differed significantly from all other crime types, $p \mathrm{~s}<.001$, whereas the estimates for the other crime types did not differ from each other, $p s>.19$. Second, there was a significant Crime Type $\times$ Estimate interaction, $F(3,912)=31.91, p<.001, \eta^{2}=.09$. A wider range between respondents' minimum and maximum estimates was found for rape $(M=9.2, S D=9.7)$ than for domestic assault $(M=6.5$, $S D=8.1)$, nondomestic battery $(M=6.4, S D=8.4)$, and mugging $(M=6.8$, $S D=8.5$ ), all $p \mathrm{~s}<.001$ (Bonferroni corrected), whereas the latter three did not differ from each other. This suggests that, although the false-report rate is believed to be higher for rape than for the other crime types, there is also a greater uncertainty about the exact frequency. Third, the Crime Type $\times$ Estimate $\times$ Occupation interaction was found to be significant, $F(3,912)=$ $9.76, p<.001, \eta^{2}=.03$. Tests of simple-simple effects revealed that police officers chose a wider range than prosecutors between their minimum and maximum estimates for rape, nondomestic battery, and mugging, $(p s<.001)$ but not for domestic assault $(F<1)$.

\section{Treatment of Crime Victims}

Respondents found it an important part of their work to make crime victims feel well treated by the criminal justice system $(M=4.7, S D=0.5)$. There was, however, a slight difference between the occupational groups, with police officers agreeing more strongly with the statement $(M=4.8$, $S D=0.5)$ than did prosecutors $(M=4.7, S D=0.5), t(399)=2.22, p<.05$, $d=.22$. Respondents also tended to think that they would be able to treat crime victims better if they could spend more time with them $(M=3.9$, $S D=1.0)$. Prosecutors $(M=4.2, S D=0.9)$ agreed more strongly with this than did police officers $(M=3.7, S D=1.1), t(398)=-5.11, p<.001, d=.51$. Opinions were more mixed in terms of whether there is enough time for contacts with crime victims $(M=2.6, S D=1.0)$. Again, prosecutors $(M=2.2$, $S D=0.9)$ perceived the lack of time to be greater than did police officers $(M=2.9, S D=1.0), t(399)=7.15, p<.001, d=.72$. 


\section{Self-Rated Knowledge}

Respondents tended to rate their own degree of knowledge about crime victims' reactions and behaviors as rather high $(M=3.5, S D=0.8)$, and police officers were more so inclined $(M=3.6, S D=0.7)$ than were prosecutors $(M=3.4, S D=0.8), t(399)=3.15, p<.01, d=.32$. As a further indicator of respondents' confidence, they tended to think that they had more knowledge than their average colleague $(M=3.4, S D=0.6), t(399)=13.59, p<.001$, $d=0.68$ (one-sample $t$ test; reference value $=3$ ). Police officers and prosecutors did not differ in this respect. Most participants (65.1\%) claimed to have tried to increase their knowledge on the issue on their own initiative. Again, no significant difference was found between the proportions of police officers and prosecutors who had done so.

\section{Discussion}

The results of the present research give insights into the beliefs of professionals within the criminal justice system regarding issues related to crime victims. The professionals surveyed expressed a perception that victims' reactions and behaviors differ as a function of crime type. For instance, victims of rape and domestic assault were thought to more often display an expressive self-presentational style and blame themselves than victims of other assaultive crimes. Although the correspondence of these beliefs to the actual frequency of victim behaviors is difficult to assess, they do indicate that a certain type of behavior is generally expected from victims of rape and domestic assault. In contrast, research indicates that the expressive style is about as common among rape victims as is the controlled style (Burgess \& Holmstrom, 1974; Frieze et al., 1987). The discrepancy between research findings and professionals' beliefs may, of course, stem from actual differences in the behaviors that crime victims display in research settings and when in contact with the legal system. Another possibility, worthy of further investigation, is that professionals hold erroneous expectations about normal crime victim behavior.

The results further indicated that respondents found nonverbal behavior to be somewhat useful when determining the veracity of a victim's statement. This belief conflicts with a large body of research showing that the nonverbal cues people rely on when trying to detect deception are unrelated to actual truthfulness (DePaulo et al., 2003; Sporer \& Schwandt, 2007; Vrij, 2008). The present finding adds to the literature by showing that professionals' 
beliefs about nonverbal reliability cues extend beyond judgments of criminal suspects and witnesses, which have been the focus of most previous research (Granhag \& Strömwall, 2004). The weight placed on nonverbal behavior is particularly alarming given the fact that respondents tended to expect an expressive self-presentational style from rape victims. Hence, there is an apparent risk of misjudgment when rape victims behave in a controlled manner. On a more positive note, however, it appears that educational efforts may be a useful step in coming to terms with misconceptions. Participants who had undergone special training placed less weight on nonverbal behavior compared with untrained participants. The data give no answer as to what particular kind of training participants had received or which educational efforts are the most effective but nonetheless imply that targeting professionals' knowledge is an important task for researchers and others with the aim to improve the criminal justice system.

Another notable set of findings concerns respondents' estimates of false reports. Allegations of rape and mugging were seen as particularly likely to be fabricated. On average, police officers thought that at least one out of six, and possibly as many as one out of four, reports of rape is false and that potentially one out of six claims of mugging is false. Although prosecutors generally made more cautious estimates, false reports of rapes were believed to be considerably more common than false reports of the other crime types. The issue of false crime allegations, especially false claims about rape, is highly controversial and has spurred a lively discussion in the media in recent years (e.g., Krantz \& Wahlgren, 2007; Ream, 2007). Some of the proposed motives behind false reports are the prospect of economic compensation, the intention to harm the accused, and the need for sympathy and attention (Kanin, 1994). One fact that is all too obvious to legal professionals is that alleged rapes are notoriously difficult to investigate, primarily because there is rarely substantial evidence other than the testimonies of the alleged victim and the suspect (Hazelwood \& Burgess, 2001). As a consequence, many rape allegations will not be proven either true or false, and the actual frequency of false allegations is therefore extremely difficult to assess. Whether correct or incorrect, the estimates reported in the present study indicate a considerable degree of suspiciousness toward rape victims. As concluded in earlier research, an overly suspicious attitude toward crime victims may result in a secondary victimization, which may increase their suffering and impede their long-term recovery (Campbell et al., 1999). Hence, it is obvious that police officers and prosecutors face a challenge in maintaining a fine balance between suspicion and acceptance when in contact with crime victims. 
The fact that police officers consistently estimated false reports to be more frequent than did prosecutors calls for an explanation. It may be that prosecutors are less suspicious toward crime victims because the two professional groups are exposed to different samples of victims. The police come in contact with all crime victims who file a report-even those who retract their allegations after a brief period of time. Prosecutors, however, come in contact only with those victims who maintain their allegations long enough for the case to be handed over to the prosecutor's office. It is possible that the lower exposure to retractors causes prosecutors to view false reports as less common. This account is plausible given that people often rely on availability as a cue to probability judgments (Tversky \& Kahneman, 1973); the more easily they come to think of examples from an event category, the more frequent or probable the type of event is thought to be. A second interpretation is that the observed results simply reflect different degrees of cautiousness when responding to the survey. In most legal systems, including the Swedish, the decisions made by prosecutors are more pivotal and consequential than those made by individual police officers. Hence, police officers may feel less accountable and freer to express their subjective opinions on controversial issues such as false crime reports. Prosecutors, however, may be motivated to portray themselves as unprejudiced, as a suspicious and speculative attitude toward crime victims may damage the public's trust in the authority. It remains for future research to establish which, if any, of the above explanations that best accounts for the present finding.

Respondents expressed concern that the time available for contact with crime victims is too scarce. This concern was particularly strong among prosecutors. Unfortunately, the insufficiency of time appears to negatively affect the manner in which crime victims are treated, as a majority of the respondents claimed that more time available would lead to improved treatment. This is an important aspect to consider when policy makers seek to improve the performance of the legal system. Ultimately, the lack of time may be conducive to misjudgments and maltreatment of crime victims. It is a well-documented social-psychological finding that time pressure, and other circumstances that limit people's information processing capacity, increase the reliance on stereotypes as a basis for social judgments (Fiske, Lin, \& Neuberg, 1999; Kaplan, Wanshula, \& Zanna, 1993). Hence, present working conditions for practitioners in the criminal justice system may function as an effective perpetuator of erroneous expectations about crime victim behaviors. This may, for instance, further discredit rape victims who do not display the expected expressive self-presentation style. 
Although the present research provided insight into police officers' and prosecutors' beliefs about crime victims, future studies should seek to address the shortcomings that are associated with this type of questionnaire research. First, there may be strong self-presentational concerns among actors in the criminal justice system. This is mainly because these agencies are highly scrutinized by the media and the public, and the expression of controversial attitudes and beliefs may elicit strong critique and loss of public support. To investigate whether the present results underestimate the extremeness of professionals' beliefs, studies should be carried out where self-presentational concerns are kept to a minimum. Second, many of the items in the questionnaire concerned perceptions of victims of violence in general. This has the disadvantage of making respondents picture an average victim, rather than a victim under clearly defined and specific circumstances, which, of course, is more akin to what respondents encounter in actual cases. One way to come to terms with this problem would be to present respondents with detailed, scenario-based descriptions and ask what behaviors would be expected from an individual victim in that situation. Third, in the areas where respondents' beliefs were found not to correspond with scientific knowledge (e.g., the value of nonverbal behavior when judging credibility), it still remains unclear what practical consequences follow from such beliefs. Equally unclear is whether the beneficial effects of education extend beyond practitioners' beliefs and influence the actual treatment of crime victims. Such questions are best addressed through the use of experimental methods.

In conclusion, criminal justice professionals' perceptions of crime victim behaviors are yet a relatively uncharted research area. The present research provides a first glance at the contents of these perceptions and points out some directions for future research efforts. The primary targets of such studies should be to draw a more complete and nuanced picture of dominant beliefs and to investigate their practical consequences on judgments of crime victim credibility. Ultimately, the main beneficiaries of this research will be crime victims as a group, whose chances of receiving an appropriate treatment are enhanced as scientific knowledge on the issue accumulates.

\section{Acknowledgments}

The author would like to thank Eva Bloch, Lisbeth Johansson, Frida Pedersson, Kajsa Rapp, Gunn Sjögren, and Leif Strömwall for their generous help at various stages of the research process. 


\section{Declaration of Conflicting Interests}

The author declared that he had no conflicts of interests with respect to his authorship or the publication of this article.

\section{Funding}

The author disclosed receipt of the following financial support for the research and/ or authorship of this article: This research was supported by the Crime Victim Compensation and Support Authority (grant nr. 8914/2006).

\section{References}

Amstadter, A. B., McCart, M. R., \& Ruggiero, K. J. (2007). Psychosocial interventions for adults with crime-related PTSD. Professional Psychology: Research and Practice, 38, 640-651.

Bard, M., \& Sangrey, D. (1986). The crime victim's book (2nd ed.). New York: Brunner/Mazel.

Bollingmo, G. C., Wessel, E. O., Eilertsen, D. E., \& Magnussen, S. (2008). Credibility of the emotional witness: A study of ratings by police investigators. Psychology, Crime \& Law, 14, 29-40.

Bond, C. F., Jr., \& DePaulo, B. M. (2006). Accuracy of deception judgments. Personality and Social Psychology Review, 10, 214-234.

Burgess, A. W., \& Holmstrom, L. L. (1974). Rape trauma syndrome. American Journal of Psychiatry, 131, 981-986.

Campbell, R., Sefl, T., Barnes, H. E., Ahrens, C. E., Wasco, S. M., \& ZaragozaDiesfeld, Y. (1999). Community services for rape survivors: Enhancing psychological well-being or increasing trauma? Journal of Consulting and Clinical Psychology, 67, 847-858.

DePaulo, B. M., Lindsay, J. J., Malone, B. E., Muhlenbruck, L., Charlton, K., \& Cooper, H. (2003). Cues to deception. Psychological Bulletin, 129, 74-118.

Fiske, S. T., Lin, M., \& Neuberg, S. L. (1999). The continuum model: Ten years later. In S. Chaiken \& Y. Trope (Eds.), Dual-process theories in social psychology (pp. 231-254). New York: Guilford.

Frieze, I. H., Hymer, S., \& Greenberg, M. S. (1987). Describing the crime victim: Psychological reactions to victimization. Professional Psychology: Research and Practice, 18, 299-315.

Granhag, P. A., \& Strömwall, L. A. (Eds.). (2004). The detection of deception in forensic contexts. Cambridge, UK: Cambridge University Press.

Hazelwood, R. R., \& Burgess, A. W. (Eds.). (2001). Practical aspects of rape investigation: A multidisciplinary approach (3rd ed.). New York: CRC Press.

Kanin, E. J. (1994). False rape allegations. Archives of Sexual Behavior, 23, 81-92.

Kaplan, M. F., Wanshula, L. T., \& Zanna, M. P. (1993). Time pressure and information integration in social judgment: The effect of need for structure. 
In O. Svenson \& A. J. Maule (Eds.), Time pressure and stress in human judgment and decision making (pp. 255-267). New York: Plenum.

Kaufmann, G., Drevland, G. C. B., Wessel, E., Overskeid, G., \& Magnussen, S. (2003). The importance of being earnest: Displayed emotions and witness credibility. Applied Cognitive Psychology, 17, 21-34.

Kaysen, D., Morris, M. K., Rizvi, S. L., \& Resick, P. A. (2005). Peritraumatic responses and their relationship to perceptions of threat in female crime victims. Violence Against Women, 11, 1515-1535.

Krantz, K., \& Wahlgren, A. (2007, March 24). Oskyldigt anklagade [Falsely accused]. Expressen, p. 18.

Lurigio, A. J. (1987). Are all victims alike? The adverse, generalized, and differential impact of crime. Crime \& Delinquency, 33, 452-467.

Norris, F. H., \& Kaniasty, K. (1994). Psychological distress following criminal victimization in the general population: Cross-sectional, longitudinal, and prospective analyses. Journal of Consulting and Clinical Psychology, 62, 111-123.

Ream, A. K. (2007, June 17). Cheers can't drown out painful truths. Chicago Tribune, p. 25.

Rose, M. R., Nadler, J., \& Clark, J. (2006). Appropriately upset? Emotion norms and perceptions of crime victims. Law and Human Behavior, 30, 203-219.

Sporer, S. L., \& Schwandt, B. (2007). Moderators of nonverbal indicators of deception: A meta-analytic synthesis. Psychology, Public Policy, and Law, 13, 1-34.

Tversky, A., \& Kahneman, D. (1973). Availability: A heuristic for judging frequency and probability. Cognitive Psychology, 5, 207-232.

Vrij, A. (2008). Detecting lies and deceit: Pitfalls and opportunities (2nd ed.). Chichester, UK: Wiley.

Weaver, T. L., \& Clum, G. A. (1995). Psychological distress associated with interpersonal violence: A meta-analysis. Clinical Psychology Review, 15, 115-140.

Wessel, E., Drevland, G. C. B., Eilertsen, D. E., \& Magnussen, S. (2006). Credibility of the emotional witness: A study of ratings by court judges. Law and Human Behavior, 30, 221-230.

Winkel, F. W., \& Koppelaar, L. (1991). Rape victims' style of self-presentation and secondary victimization by the environment: An experiment. Journal of Interpersonal Violence, 6, 29-40.

Wirtz, P. W., \& Harrell, A. V. (1987). Assaultive versus nonassaultive victimization: A profile analysis of psychological response. Journal of Interpersonal Violence, 2, 264-277.

\section{Bio}

Karl Ask is a researcher and lecturer at the department of psychology, University of Gothenburg, Sweden. He received his $\mathrm{PhD}$ from the University of Gothenburg in 2006. His research interests include investigative psychology, witness psychology, and motivation and emotion in legal settings. 